\title{
Свободный порт Владивосток: проблемы становления
}

\section{Татьяна Попова*, Галина Павленко}

Дальневосточный федеральный университет, Владивосток, Россия

\author{
Информация о статье \\ Поступила в редакцию: \\ 08.11 .2019 \\ Принята \\ к опубликованию: \\ 04.02 .2020 \\ УДК $332.122 ; 332.135$ \\ JEL R11
}

\section{Ключевье слова:}

Свободный порт Владивосток, преференции, резидент, свободная таможенная зона

Keywords:
Free Port of Vladivostok,
preferences, resident, free
customs zone

\begin{abstract}
Аннотация
В работе рассматриваются особенности правового режима и основные проблемы становления Свободного порта Владивосток. Установлено, что решение выявленных проблем возможно только в тесном взаимодействии резидентов СПВ с таможней, налоговыми органами и Корпорачией по развитию Дальнего Востока.

Кроме того, в ходе исследования выяснено, что в ходе реализации концепцуии Свободного порта Владивосток постепенно произошел отход от первоначального замысла, в частности, от создания приоритетного режима, когда акцент делался на привлечение крупных зарубежных инвесторов, в сторону вовлечения в режим СПВ малого и среднего отечественного предпринимательства.
\end{abstract}

\section{Free Port of Vladivostok: Issues of Formation}

Tatiana Popova, Galina Pavlenko

\section{Abstract}

As of January 1, 2019, there were 1645 residents in the register of the Free Port of Vladivostok as agaist 275 of those in August 2017. Of these there were those who dealt with growing Christmas trees, producing bio-additives and setting films, but some of the residents had to do with the infrastructure - logistics services, marine terminals operations and construction, etc. The paper deals with the specifics of the Free Port of Vladivostok legal regime and main development issues. The main development issues of the Free Port of Vladivostok include: inadequate application of the Customs procedure of the free Customs zone, raising the appropriate funding is still a major challenge for the residents; inoperability of the preferences for receiving a land plot without an auction. The solution of these issues is possible only in close cooperation of the Free Port of Vladivostok residents with the Customs, Tax authorities and with the Far East Development Corporation. In addition, during the process of investigation it was found that in the course of the Free Port of Vladivostok concept implementation there was a gradual receeding from the original plan, in particular,from setting up the priority regime on attracting major foreign investors to involving small and medium-sized domestic enterprises into the Free Port of Vladivostok regime.

\footnotetext{
* Автор для связи: popova_tni@dvfu.ru
}

DOI: https://dx.doi.org/10.24866/2311-2271/2019-4/35-41 


\section{Введение}

За период с 2009 по 2015 гг. в государственной политике развития востока страны произошла смена акцентов. В 2009-2012 гг. основными задачами являлись ввод в регион государственных инвестиций, поддержание уровня государственного спроса и увеличение на этой основе темпов экономическго роста и масштабов экономики. С 2013 г. в связи с ухудшением общей макроэкономической ситуации в России вектор развития был перенаправлен на наращивание финансовых вливаний в инфраструктуру институциональных новаций на Дальнем Востоке, которые призваны сделать регион процветающим и современным [1]. Одной из таких новаций, которая была предложена в качестве абсолютно нового и, безусловно, эффективного инструмента развития, является внедрение концепции Свободного порта Владивосток (далее - СПВ).

Цель исследования заключается в выявлении особенностей правого режима основных проблем становления СПВ.

В процессе поиска и изучения причинно-следственных связей экономических явлений были применены общенаучные подходы (системный, комплексный, проектный, логический). Методологическую основу исследования составили методы анализа и синтеза, систематизация и классификация, моделирование и визуализация, индукция и дедукция, сравнение и обобщение.

\section{Теоретическая основа исследования}

Понятие «свободный порт» появилось благодаря итальянскому термину «порто-франко» (porto franco), который исторически означал морскую гавань с правом беспошлинного ввоза иноземных товаров. Данный термин прочно вошел в экономический лексикон в связи с тем, что первые свободные порты были открыты именно в Италии в XVI в. [2]. В настоящее время свободные порты выступают одним из видов свободных экономических зон. Они представляют собой специально выделенные портовые территории с льготными таможенным, налоговым, валютным режимами, которые стимулируют приток иностранного капитала, развитие совместных производств, экспортно-импортных операций и т.д. Конечной целью функционирования свободного порта является развитие экономики прилегающей к порту территории за счет реализации ее резко возрастающего внешнеторгового и инвестиционного потенциалов .

Россия имеет опыт создания и функционирования свободных портовых зон. Так с 1819 по 1859 гг. режим порто-франко действовал в г. Одессе. С 1828 по 1838 гг. - на Камчатке. В 1856 г. право беспошлинной торговли было введено в г. Николаевске-на-Амуре, позже распространено на г. Владивосток, Посьет и другие порты Приморской области. В 1860-1862 гг. была разрешена двусторонняя беспошлинная торговля по сухопутной границе с Китаем почти всеми товарами [2]. Право беспошлинной торговли, установившееся на всей территории Дальнего Востока России, было отменено в 1909 г.

Статус свободного порта дал очень многое Дальневосточному региону, освоение которого происходило в условиях оторванности от основной части страны, отсутствия капитала, низкого качества жизни, бытовой и административной неустроенности. По оценке специалистов, вторая половина XIX в. для Дальнего Востока России прошла под знаком развития иностранной торговли. Объем только американского экспорта, осуществлявшегося через порты Тихого океана, за период с 1866 по 1881 гг. возрос в 63 раза. Общий объем грузооборота города Владивостока в 1883-1899 гг. увеличился в 7 раз. Судя по отче- 
там различных должностных лиц Приамурского края, американские сельскохозяйственные машины продавались крестьянам на льготных условиях, а многие привозные изделия были дешевле и качественнее, чем производившееся на местах отечественные. По оценке современников, такая торгово-снабженческая деятельность приносила несомненную пользу Дальнему Востоку. И в прошлом, и сейчас свободный порт Владивосток - это своеобразное окно, открывающееся в страны Азиатско-Тихоокеанского региона, навстречу большим возможностям развития свободной международной торговли.

\section{Основные направления исследования и их обсуждение}

Особенности правого режима СПВ. Под СПВ понимается часть территории Приморского края, на которой в соответствии с Федеральным законом N212 от 13.07.2015 и иными Федеральными законами устанавливаются меры государственной поддержки предпринимательской деятельности. СПВ создается на 70 лет [3]. Была создана система специальных субъектов, отвечающих за реализацию закона: Корпорация развития Дальнего Востока, Департамент территорий опережающего развития и инфраструктуры Минвостокразвития России, Ассоциация поддержки резидентов Свободного порта Владивосток, Агентсво Дальнего Востока по привлечению инвестиций и поддержки экспорта, Наблюдательный совет Свободного порта Владивосток, Консультативный совет по работе с участниками внешнеэкономической деятельности. Территория СПВ включает 22 муниципальных образования, 5 регионов.

В плане законопроектной работы Правительства Российской Федерации на 2020 г. - внесение изменений в ст. 4 Федерального закона «О свободном порте» (в части расширения границ СПВ).

Под резидентом СПВ понимается индивидуальный предприниматель или являющееся коммерческой организацией юридическое лицо, государственная регистрация которых осуществлена на территории СПВ согласно законодательству Российской Федерации (за исключением государственных и муниципальных унитарных предприятий), которые заключили в соответствии с настоящим Федеральным законом соглашение об осуществлении деятельности и включены в реестр резидентов СПВ [3].

Завку на резидентство в СПВ можно подать с помощью online сервиса на сайте www.erdc.ru или направить бумажную и электронную версию заявки и документов в АО «Корпорация развития Дальнего востока» или ее дочерние организации.

Комплект документов для СПВ:

- заявка (приказ Минвостокразвития России №170);

- бизнес-план (Приказ Минвостокразвития России №187);

- учредительные документы (для юридических лиц);

- свидетельство о государственной регистрации /лист записи ЕГРЮЛ);

- свидетельство о постановке на учет в налоговом органе.

Критерии оценки заявки и документов:

- регистрация осуществлена на территории СПВ;

- реализация проекта планируется на данной территории;

- объем капитальных вложений не менее 5 млн руб.;

- осуществление не запрещенных видов предпринимательской деятельности. 
На 1 января 2019 г. в реестре СПВ находятся 1645 резидентов против 275 в августе 2017 г. Среди них есть такие, которые занимаются выращиванием новогодних елок, производством биодобавок и съемкой фильмов, но часть резидентов имеет отношение к инфраструктуре - логистическим услугам, деятельности морских терминалов и строительству и пр. [4].

К наиболее значимым резидентам Свободного порта Владивосток можно отнести:

- АО «Восточный порт» - строительство 3-й очереди углепогрузочного комплекса в порту Восточный, 619 рабочих мест;

- АО «Международный аэропорт «Хабаровск» - строительство нового пассажирского терминала международного аэропорта в г. Хабаровске, 549 рабочих мест;

- ООО «Организация многопрофильного обслуживания - БК» - капитальное строительство микрорайона «Шестой» в г. Большой камень (Приморский край), 75 рабочих мест;

- ООО «Эльбрус» - создание промышленного комплекса по добыче и переработке рыбы в пос. Моряк-Рыболов (Приморский край, Ольгинский район), 189 рабочих мест;

- ООО «Приморская золоторудная компания» - разработка золоторудных месторождений «Золотой» и «Золотой Северный» (Приморский край, Партизанский район), 130 рабочих мест.

В табл. 1 представлены преференции резидентам СПВ.

Таблиия 1

Преференции Свободного порта Владивосток

\begin{tabular}{|c|c|c|}
\hline $\begin{array}{c}\text { Административная } \\
\text { поддержка } \\
\end{array}$ & Налоговые преференции резидентам & Таможенные льготы \\
\hline $\begin{array}{l}\text { Режим «Одного окна» для } \\
\text { инвестора }\end{array}$ & $\begin{array}{l}0 \% \text { - налог на прибыль. При этом в те- } \\
\text { чение } 5 \text { лет } 0 \% \text { в федеральный бюджет, } \\
\text { не более } 5 \% \text { в региональный бюджет } \\
\text {.(нерезидентам - } 20 \% \text { налог на прибыль) }\end{array}$ & \multirow{6}{*}{\begin{tabular}{l}
\multicolumn{2}{|c}{ Режим } \\
свободной таможен- \\
ной зоны для рези- \\
дентов установлен \\
Соглашением по \\
вопросам свободных \\
(специальных, осо- \\
бых) экономических \\
зон на таможенной \\
территории Тамо- \\
женного союза и \\
таможенной проце- \\
дуры свободной \\
таможенной зоны от \\
18 июня 2010 г. в \\
целях применения \\
таможенной проце- \\
дуры свободной \\
таможенной зоны \\
территория свобод- \\
ного порта Владиво- \\
сток приравнивается \\
к особой экономиче- \\
ской зоне.
\end{tabular}} \\
\hline $\begin{array}{l}\text { Сокращенные сроки прове- } \\
\text { дения контрольных проверок }\end{array}$ & $\begin{array}{l}12 \% \text { следующие пять лет (льгота по ре- } \\
\text { гиональной части налога устанавливает- } \\
\text { ся субъектом Российской Федерации) }\end{array}$ & \\
\hline $\begin{array}{l}\text { Право управляющей компа- } \\
\text { нии на защиту резидентов в } \\
\text { суде }\end{array}$ & $\begin{array}{l}0 \% \text { - налог на землю (первые три года) ( } \\
\text { нерезидентам предусмотрен налог на } \\
\text { землю от } 0,3 \% \text { до } 1,5 \%)\end{array}$ & \\
\hline $\begin{array}{l}\text { Возможность получения зе- } \\
\text { мельных участковв аренду } \\
\text { без торгов, по кадастровой } \\
\text { стоимости }\end{array}$ & $\begin{array}{l}\text { 0\% - налог на имущество с момента } \\
\text { постановки на балансовый учет в рамках } \\
\text { деятельности резидента СПВ (не рези- } \\
\text { дентам - } 2,2 \% \text { - налог на имущество) }\end{array}$ & \\
\hline $\begin{array}{l}\text { Привлечение иностран } \\
\text { рабочей силы без квот }\end{array}$ & $\begin{array}{l}\text { Единый социальный налог снижен с } 30 \% \\
\text { до } 7,6 \% \text {, а также страховые взносы в } \\
\text { ПФР, ФСС, ФОМС. }\end{array}$ & \\
\hline $\begin{array}{l}\text { Возможность возмещения } \\
\text { НДС }\end{array}$ & $\begin{array}{l}\text { Резиденты имеют право на возмещение } \\
\text { НДС в заявительном порядке. Для этого } \\
\text { нужно предоставить налоговую деклара- } \\
\text { цию и договор (копию) поручительства } \\
\text { управляющей компании. }\end{array}$ & \\
\hline
\end{tabular}

Источник: составлено автором по [3] 
Резиденты СПВ смогут получать кредит по новой льготной системе. Так, с 2020 г. дальневосточный бизнес, занятый в СПВ, сможет брать кредит на развитие проектов с субсидированием процентных ставок. Субсидия будет даваться на часть ставки. Таким образом, процентная ставка станет меньше рыночной примерно на размер аналогичной ставки Центрального Банка России.

\section{Основные проблемы в СВП}

На территории СПВ применяется таможенная процедура свободной таможенной зоны (далее - СТ3). Однако используют этот режим далеко не все резиденты. Этот вопрос обсуждался в рамках Восточного экономического форума - 2018 на секции «Свободный порт Владивосток: особенности таможенного администрирования». Ниже приводим часть дискуссии на этой сессии.

Михаил Орлов, партнер, руководитель Департамента налогового и юридического консультирования КПМГ в России и СНГ: «В настоящее время насчитывается 1645 резидентов в СПВ и лишь примерно 1\% воспользовались созданием СТЗ. Чем это может быть вызвано?

Антон Скорик, председатель Ассоциации поддержки резидентов СПВ, руководитель ООО «Ренессанс» в ответ предположил, что проблема в высокой стоимости создания СТЗ (требуется минимум 3 млн руб. на организацию одной таможенной зоны).

Дмитрий Кудинов, генеральный директор ООО «Мазда Соллерс Мануфэкчуринг Рус»: «Мы рассматривали вопрос об использовании СТЗ. Одним из условий применения таможенной процедуры свободной таможенной зоны (СТ3) является создание зоны таможенного контроля при условии оборудования и обустройства участка резидента для целей таможенного контроля. Однако создание такой зоны - это дорогостоящее мероприятие. Поэтому мы разработали свою процедуру. Мы четко знаем, к кому обратиться при возникновении вопросов: Таможенный пост - ДВТУ - ФТС. То есть без процедуры СТЗ можно осуществлять внешнеэкономическую деятельность в рамках Свободного Порта Владивосток».

Юрий Тямушкин, генеральный директор АО «Ванино Транс Уголь» (АО «ВТУ») поддержал Дмитрия Кудинова, сказав, что для АО «ВТУ» бессмысленно создавать СТЗ, т.к надо оградить 350 га территории, а на это потребуется 350 млн долл. США. А оборудование компании на сегодняшний день обладает производительностью на 100 млн долл. США.

Согласился с предыдущими ораторами и Сергей Колесников, президент корпорации «ТехноНИКОЛЬ», который также рассказал о том, что не стал создавать СТЗ в связи с высокой стоимостью и сжатыми сроками реализации.

Другой серьезной проблемой для резидентов остается привлечение необходимого финансирования. Ставки по кредитам, которые предлагают банки, слишком высоки. Для решения данного вопроса Минвостокразвития Российской Федерации разработало механизм субсидирования процентной ставки для резидентов ТОР и СПВ.

В.В. Горчаков в статье «Свободный порт Владивосток: проблемы становления и перспективы развития» пишет, что широкий спектр налоговых льгот, которые предоставляет СПВ своим резидентам, недостаточно привлекателен для малого бизнеса, находящихся на упрощенной системе налогообложения либо работающих по патенту [5]. Самый примитивный анализ налоговых платежей и льгот, которые возможны для резидентов СПВ, показывает, что 
существующий набор позволит создать особые условия для бизнесов, абсолютно «белых» с точки зрения выплаты заработной платы (крупный бизнес). Для малого и среднего предпринимательства работа в существующих условиях часто выгоднее, чем легальное резидентство в СПВ. Идея введения единого налога по-прежнему активно обсуждается [5].

Кроме того, основные нарекания резидентов СПВ вызывает неработоспособность преференции получения земельного участка без аукциона. С одной стороны, требуется кардинальное повышение эффективности работы региональных и муниципальных властей без девальвации законных прав резидентов на участки, с другой, - сами предприниматели все чаще стали использовать данную преференцию для создания преимуществ в недобросовестной конкуренции. Для выхода из подобных ситуаций подготовлен ряд поправок в законодательство, которое сейчас проходят согласование в органах исполнительной власти [6].

\section{Заключение}

Таким образом, выявлены особенности правого режима и обозначены основные проблемы СВП. Решение перечисленных проблем возможно только в тесном взаимодействии резидентов СПВ с таможней, налоговыми органами и Корпорацией по развитию Дальнего Востока.

Можно присоединится к выводам авторов А.С. Ващук и О.Е. Шишкиной о том, что постепенно произошел отход от первоначального замысла, в частности, от создания приоритетного режима, когда акцент делался на привлечение крупных зарубежных инвесторов, в сторону вовлечения в режим СПВ малого и среднего отечественного предпринимательства [7].

\section{Список источников / References}

1. Минакир П.А. Новая восточная политика и экономические реалии. Дальневосточный ученый, 2015, №2, сc. 7-11. N 15.29.07.2015г. [Minakir P.A. Novaya vostochnaya politika i e`konomicheskie realii [New Eastern policy and economic realities]. Dal 'nevostochny $\mathrm{j}$ ucheny $\mathrm{j}$ = Far Eastern Scientist, 2015, no. 2, pp. 7-11.]

2. Матвеев Н.П. Краткий исторический очерк г. Владивостока. Владивосток, Тихоокеанское изд-во «Рубеж», 2012. 512 с. [Matveev N.P. Kratkij istoricheskij ocherk g. Vladivostoka [A brief historical outline of the city of Vladivostok]. Vladivostok, Pacific Publishing House "Rubezh", 2012. 512 p.]

3. Федеральный закон от 13.07.2015 № 212-Ф3 (ред. от 03.07.2016) «О свободном порте Владивосток» [Federal'ny`j zakon ot 13.07.2015 № 212-FZ (red.ot 03.07.2016) «O svobodnom porte Vladivostok» [Federal Law of July 13, 2015 No. 212-FZ (as amended on July 3, 2016) "On the Free Port of Vladivostok"]. Available at: http://www.consultant.ru/document/cons_doc_law_182596/(accessed 03.07.2019)

4. Аналитический обзор. Инфраструктура и рынки. Дальний Восток. INFRA ONE, Первая инфраструктурная компания, Москва, 2018. [Analiticheskij obzor. Infrastruktura i ry`nki. Dal`nij Vostok [Analytical review. Infrastructure and markets. Far East]. INFRA ONE Publ., First Infrastructure Company, Moscow, 2018.]

5. Горчаков В.В. Свободный порт Владивосток: проблемы становления и перспективы развития. Таможенная политика на Дальнем Востоке, 2015, №4 (73), сс. 26-30. [Gorchakov V.V. Svobodny`j port Vladivostok: problemy` stanovleniya i perspektivy` razvitiya [Free port of Vladivostok: problems of formation and development prospects]. 
Tamozhennaya politika na Dal'nem Vostoke = Customs policy in the Far East, 2015, no. 4 (73), pp. 26-30.]

6. Тихонов Д. Достигнутые результаты меняют взгляд на вещи. Корпорация развития Дальнего Востока, 2018. [Tixonov D. Dostignuty'e rezul'taty` menyayut vzglyad na veshhi [The results are changing the way things look]. Far East Development Corporation, 2018.]

7. Шишкина О.Е., Ващук А.С. История создания свободного порта Владивосток: от идей к реализации закона. Россия и АTP, 2019, №3, cc. 161-179. [Shishkina O.E., Vashhuk A.S. Istoriya sozdaniya svobodnogo porta Vladivostok: ot idej $\mathrm{k}$ realizacii zakona [The history of the creation of the free port of Vladivostok: from ideas to the implementation of the law]. Rossiya $i$ ATR $=$ Russia and Asia-Pacific Region, 2019, no. 3., pp. 161-179.]

\section{Сведения об авторах / About authors}

Попова Татьяна Николаевна, кандидат экономических наук, доцент кафедры мировой экономики, Школа экономики и менеджмента, Дальневосточный федеральный университет. 690022 Россия, г. Владивосток, о-в Русский, кампус ДВФУ, корпус G. E-mail: popova_tni@dvfu.ru Tatiana N. Popova, Candidate of Economic Sciences, Associate Professor of World Economics Department, School of Economics and Management, Far Eastern Federal University. Building G, FEFU campus, Russky Island, Vladivostok, Russia 690922. E-mail: popova_tni@dvfu.ru

Павленко Галина Федоровна, кандидат технических наук, доцент кафедры бизнесинформатики и экономико-математических методов, Школа экономики и менеджмента, Дальневосточный федеральный университет. 690022 Россия, г. Владивосток, о-в Русский, кампус ДВФУ, корпус G. E-mail: pavlenko.gf@dvfu.ru

Galina F. Pavlenko, Candidate of Technical Sciences, Associate Professor of Department of Business Informatics and Economic and Mathematical Methods, School of Economics and Management, Far Eastern Federal University. Building G, FEFU campus, Russky Island, Vladivostok, Russia 690922.

E-mail: pavlenko.gf@dvfu.ru 